NBER WORKING PAPER SERIES

\title{
INFORMATION AND EXTERNALITIES IN SEQUENTIAL LITIGATION
}

\author{
Xinyu Hua \\ Kathryn E. Spier \\ Working Paper 10943 \\ http://www.nber.org/papers/w10943
NATIONAL BUREAU OF ECONOMIC RESEARCH
1050 Massachusetts Avenue
Cambridge, MA 02138
December 2004

The views expressed herein are those of the author(s) and do not necessarily reflect the views of the National Bureau of Economic Research.

(C) 2004 by Xinyu Hua and Kathryn E. Spier. All rights reserved. Short sections of text, not to exceed two paragraphs, may be quoted without explicit permission provided that full credit, including $\odot$ notice, is given to the source. 
Information and Externalities in Sequential Litigation

Xinyu Hua and Kathryn E. Spier

NBER Working Paper No. 10943

December 2004

JEL No. K13, K41, D83

\begin{abstract}
$\underline{\text { ABSTRACT }}$
The information created and disseminated through the litigation process can have social value. Suppose a long-lived plaintiff is suing a defendant for damages sustained in an accident. The plaintiff may suffer similar damages in future accidents involving different defendants. Potential injurers update their beliefs after observing the first case and subsequently fine-tune their precautions to avoid accidents. The joint incentive of the plaintiff and the first defendant to create public information through litigation is too small. The optimal liability rule trades off providing future injurers with incentives to take precautions and providing the plaintiff with incentives to create information.

Xinyu Hua

Kellogg School of Management

Northwestern University

2001 Sheridan Road

Evanston, IL 60208

xyhua@kellogg.northwestern.edu

Kathryn E. Spier

Kellogg School of Management

Northwestern University

2001 Sheridan Road

Evanston, IL 60208

and NBER

k-spier@kellogg.northwestern.edu
\end{abstract}




\title{
Information and Externalities in Sequential Litigation
}

\author{
XINYU HUA AND KATHRYN E. SPIER ${ }^{1}$
}

November 19, 2004

The information created and disseminated through the litigation process can have social value. Suppose a long-lived plaintiff is suing a defendant for damages sustained in an accident. The plaintiff may suffer similar damages in future accidents involving different defendants. Potential injurers update their beliefs after observing the first case and subsequently fine-tune their precautions to avoid accidents. The joint incentive of the plaintiff and the first defendant to create public information through litigation is too small. The optimal liability rule trades off providing future injurers with incentives to take precautions and providing the plaintiff with incentives to create information.

\section{Introduction}

In 1989, the Exxon Valdez ran aground off the coast of Alaska and spilling some 11 million gallons of crude oil into Prince William Sound. The spill affected approximately 1,500 miles of Alaska's coastline killing billions of salmon, on order of a million seabirds, thousands of otters, and hundreds of bald eagles. ${ }^{2}$ Exxon paid about $\$ 2.5$ billion to cover the two years of cleanup efforts. After investigations to assess the value of the environmental damages themselves, Exxon settled in 1991 with the state of Alaska for \$1 billion. The settlement also included a so-called "reopener clause" that allowed the government to seek an additional $\$ 100$ million in the future if new damages were discovered within a decade. ${ }^{3}$

\footnotetext{
* The authors are from the Kellogg School of Management and the Kellogg School of Management and NBER, respectively. We would like to thank Rick Brooks, Omri Ben Shahar, Eberhard Feess, A. Mitchell Polinsky, Eric Rasmusen, Hans-Bernd Schäfer, Warren Schwartz, and seminar participants at Georgetown Law School, the International Seminar of the New Institutional Economics, and the American Law and Economics Association Meetings for helpful comments. We also would like to thank both the Georgetown University Law Center and the Max Planck Institute for their generous hospitality. The second author thanks the Searle Fund for financial support.

2 WILKINSON [2002].

${ }^{3}$ Carlton [2001].
} 
This paper argues that the accurate determination of damages -- even those that may become known years later -- provides those engaging in similar risky activities with valuable information for future decision-making. This point is of course not unique to environmental damages. Manufacturer liability and litigation for product-related harms does more than simply provide manufacturers with better incentives to design safer products and disclose known product risks to consumers. The litigation process is also a mechanism for creating and disseminating information about these risks. The information that is made public through litigation puts both product users and other manufacturers in a better position to take precautions to mitigate their future risks. ${ }^{4}$

Formally, this paper considers a simple framework where a single plaintiff faces a sequence of defendants. ${ }^{5}$ The first accident has already occurred, while the accidents involving future defendants have not. The accidents are similar in the sense that the plaintiff's damages from the accidents are positively correlated. Litigation is socially valuable in this setting because pretrial investigations and trials provide information about accident risks to the future defendants. The future defendants can then fine tune their precautions to avoid future injuries. We ask several questions. First, is the plaintiff's decision to litigate the first case socially efficient? Second, how might liability rules be adjusted in light of a divergence? Finally, does the presence of asymmetric information change these answers?

We first consider a case where the plaintiff and the defendants are symmetrically uninformed about the damages from an accident. In the Exxon Valdez case, it was not

\footnotetext{
${ }^{4}$ Individuals who have been exposed to asbestos, for example, can reduce the chance of developing severe asbestos-related illnesses by avoiding cigarettes and dust.

${ }^{5}$ The analogous case of a single defendant facing a sequence of plaintiffs was considered in an earlier version of this manuscript, HUA AND SPIER [2003].
} 
initially clear how high the environmental damages were. Careful investigations before the trial allowed the litigants to more accurately pinpoint the damages that arise from oil spills. If there is no possibility of a similar case arising in the future then the first case will surely settle -- there is no sense spending money to determine the precise level of damages when a quick settlement can be obtained at the expected damage level. When similar cases may arise in the future, however, then settlement negotiations could fail. In particular, the long-lived plaintiff can benefit from the effect that the information from the first trial has on the future defendants' precautions. ${ }^{6}$ The plaintiff's incentive to generate information is not socially efficient, however, since the future defendants typically capture some of the social benefit of increased information.

The symmetric information case also gives us insights into the design of liability rules. Taking the plaintiff's decision to settle or litigate the first case as fixed, the efficient liability rule puts $100 \%$ responsibility on the player who needs to be given incentives for care -- the future defendants in our example. But the plaintiff's settlement decision is endogenous and hinges on the liability rule. When the plaintiff bears no responsibility for his own damages he captures none of the information value and will therefore prefer to settle the first case. To put it somewhat differently, putting $100 \%$ responsibility on the defendants will chill the flow of information. The optimal liability rule will balance the need to provide defendants with appropriate incentives and the need to create public information and will often feature shared responsibility for accident harms.

\footnotetext{
${ }^{6}$ Although our stylized model has the information appearing in the courtroom, much of it is discovered through pretrial investigations. An open settlement following pretrial discovery potentially reveals information to the public as well.
} 
These results may change when the plaintiff and the first defendant are asymmetrically informed about the damages. Suppose that the plaintiff has private information about the damages he has sustained and the first defendant can make a single take-or-or-leave-it offer before trial. Bargaining failures arise in equilibrium: when the plaintiff's damages are sufficiently high the plaintiff will reject the defendant's offer and go to trial where litigation costs are incurred. ${ }^{7}$ In short, value is destroyed as the litigants engage in rent-seeking activities and take tough bargaining stances in an attempt to grab a greater share of the bargaining surplus. When the plaintiff's long-run value from information disclosure is small then the equilibrium level of litigation activity is socially excessive.

These results do not imply that the litigation process is the only way -- or necessarily the best way -- of disseminating information about harmful activities to the public. First, responsibility for investigations could be delegated to government agencies or public interest groups. This is especially relevant for lawsuits involving only short-run litigants who have no private stake in information disclosure. Second, private parties might prefer to operate outside of the legal arena, investigating harm and disseminating this information to the public without filing suit at all. The litigation process may have an advantage over these alternatives, however, because it serves an "auditing role." The plaintiff in our model would like to inflate the public's perception of damages in order to induce greater precautions and public interest groups might exhibit similar tendencies. The adversarial process may mitigate bias and create better incentives for information gathering (DEWATRIPOINT AND TIROLE [1999]). Furthermore, the oversight of a judge may help to accurately and credibly link the court award

\footnotetext{
7 Although the framework with a take-it-or-leave-it offer, based on BEBCHUK [1984], seems extreme, the results are actually more general. The bargaining environment features common values and any bargaining game will lead to negotiation breakdowns with positive probability. See the mechanism-design model of SPIER [1994b].
} 
(or court-approved settlement) with the true economic losses.

This paper contributes to the large literature on settlement of litigation (see the surveys of DAUGHETY [1999] and HAY AND SPIER [1998]. Although most of the early literature focused on disputes between a single defendant and a single plaintiff -- often with asymmetric information -- more recent papers have considered externalities among multiple litigants. ${ }^{8}$ Externalities can create strong incentives for parties to consolidate their claims (CHE [1996], [2002] and SPIER [2002]). Public policies, such as precedent, also create externalities and lead parties to adjust their settlement strategies (CHE AND YI [1993]). ${ }^{9}$ DAUGHETY AND REINGANUM [1999], [2002] argue that confidential settlements are a way for the defendant to keep information about the lawsuit a secret from future plaintiffs. In contrast, the plaintiff in our model would like to publicize high damages to encourage greater precautions and avoid being similarly harmed in the future. None of these papers consider the ex post incentive effects identified here.

Second, our paper adds a new twist to the debate over the social value of accuracy in adjudication (see the survey by KAPLOW [1998]). KAPLOW AND SHAVELL [1996] have argued that the accurate assessment of damages at trial can be valuable in creating better ex ante incentives. If an injurer knows ex ante that his actions could lead to higher social losses -- and that he will be held liable for the higher damages -- then he will take greater care to avoid the accident. If, on the other hand, if the injurer lacks the knowledge that the social harm will be

\footnotetext{
8 Even in the absence of private information, externalities can lead settlement negotiations to fail. KORNHAUSER AND REVESZ [1994a], [1994b] look at multiple defendant lawsuits under joint and several liability, focusing on the externalities in settlement decisions. SPIER [2003] looks at externalities between multiple plaintiffs who are suing a potentially insolvent defendant. SPIER AND SYKES [1998] explore the externalities between settling plaintiffs and debtholders.

${ }^{9}$ MILLER [1998] presents a survey, highlighting the conflict of interest between the plaintiffs and the (often self-appointed) attorney.
} 
unusually large (and cannot easily acquire the information) then accuracy has no social value. Since the accurate determination of damages at trial is very costly, their argument goes, society would be better served by policies where injurers are held responsible only for the damages that they could have reasonably anticipated ex ante. ${ }^{10}$ This paper takes a different perspective: accuracy in adjudication creates social value by informing future players about the risks associated with their activities and creating better ex post incentives.

Finally, this paper adds to the small but growing literature on the divergence between the private and social incentives to litigate and settle lawsuits. SHAVELL (1997) argues that the incentives of private parties to use the legal system typically diverge from what is best for society as a whole. The resources wasted in litigation do not always have a corresponding social benefit. Costs would be saved -- and the proper ex ante incentives maintained -- if the parties settled for the "average" judgment instead. ${ }^{11}$ In contrast to the literature, this paper takes a forward-looking perspective by arguing that early settlement can compromise the future incentives of the players.

The next section presents the general framework. The third section assumes that the players are symmetrically uninformed about future damages and shows that the private incentive to settle is stronger than the social incentive. The fourth section presents an example where the plaintiff is initially privately informed about his damages at date 1 , and shows that the private incentive to settle may be either too weak or too strong. The final section concludes.

${ }^{10}$ SPIER [1994a] argues that accuracy is valuable when ex ante care levels affect the level of damages, not just the probability of an accident. KAPLOW AND SHAVELL [1994] consider the value of accuracy when the main issue at trial is liability, not damages.

11 Disagreements over liability, on the other hand, can create incentives to settle too often in the sense that defendants will take too little care in anticipation of a future settlement (SPIER [1997]). 


\section{The Model}

There are $N+1$ players: a plaintiff $(P)$ who has suffered harm, $h$, a current defendant $\left(D_{1}\right)$ who has caused the harm, and a group of $N-1$ future defendants $\left(D_{2}, D_{3}, \ldots D_{N}\right)$ who may harm the plaintiff at a future date. All players are risk-neutral. We assume that the damages caused by the $N$ defendants are perfectly correlated; in the event of an accident the future defendants cause harm $h$ as well. ${ }^{12}$ The damages are drawn from distribution $f(h)$ on $[0, \infty)$ with mean $\bar{h}$. We assume that $[1-F(h)] / f(h)$ is strictly decreasing in $h^{13}$ Although this distribution is common knowledge, the realization of $h$ is not observed. If the plaintiff pursues litigation against the first defendant, however, then investigations will be conducted and the true value of $h$ will be accurately verified and publicly disclosed.

In the event of an accident, the court will force the responsible defendant to pay fraction $\alpha \in[0,1]$ of the plaintiff's damages. The parameter $\alpha$, the "liability rule," is a choice variable for a social planner who seeks to maximize social welfare. Trials are assumed to be costly: the plaintiff's litigation cost is $k_{P}$ and the defendant's litigation cost is $k_{D}$ and we let $k$ represent the total litigation cost. The "American Rule" is in effect: each side bears its own litigation costs. $^{14}$

The future defendants are fully aware of the existence of the first case and take careful note of its disposition, including the precise value of $h$ if the first case goes to trial. These defendants also play an active role in preventing future accidents: Each future defendant $D_{i}$,

12 This simplifying assumption is not overly restrictive. The basic result would hold if damages were correlated instead. If the defendants were irrational, however, and overreacted to information then clearly the value of information would be compromised.

${ }^{13}$ This monotone hazard rate assumption is satisfied by many common distributions.

${ }^{14}$ Our basic results do not hinge on the cost allocation rule. 
$i=2, \ldots . N$, makes non-verifiable precautions, $x_{i}$, to reduce the probability of an accident. ${ }^{15}$ Formally, the probability that $\mathrm{D}_{\mathrm{i}}$ will cause an accident is $\pi\left(x_{i}\right)=1-x_{i}$ and $c\left(x_{i}\right)$ is $\mathrm{D}_{\mathrm{i}}$ 's associated cost of precautions. We assume that the cost function is strictly increasing and convex and satisfies the following conditions: $c(0)=0, c^{\prime}(x)=0, \operatorname{Lim}_{x \rightarrow 1} c^{\prime}(x)=\infty$, and $c^{\prime \prime \prime}(x) \leq 0 .{ }^{16}$

The timing of the game is as follows. At date $1, P$ and $D_{l}$ attempt to negotiate a settlement. If negotiations succeed then the first round ends and if negotiations fail the first case goes to trial where $h$ is verified and publicly disclosed. $D_{l}$ is forced to pay $\alpha h$ to the plaintiff and the defendant and plaintiff bear litigation costs $k_{d}$ and $k_{p}$, respectively. At date 2 the future defendants choose their precautions. Accidents subsequently occur as described above and the plaintiff and the responsible defendant engage in settlement negotiations. If negotiations fail the case goes to trial where the defendant pays $\alpha h$ to the plaintiff and litigation costs $k_{d}$ and $k_{p}$ are borne. Note that there may be anywhere between 0 and $\mathrm{N}$ new accidents. The assumption that future defendants choose precautions and cause accidents at exactly the same time is for expository convenience; the results would be unchanged if they arrived in sequence instead. ${ }^{17}$

Note that settlement negotiations always take place under symmetric information. The plaintiff's share of the bargaining surplus (if a positive surplus exists) is represented by a parameter $\theta$ and we make the simplifying assumption that $(1-\theta) k_{p}-\theta k_{d}=0$. This

\footnotetext{
${ }^{15}$ Note that we do not consider the precautions taken by the first defendant. A firm selling automobiles, for example, could certainly take actions to reduce the possible damage level to buyers. (If these precautions were observable, however, then firms could internalize these through ex-ante pricing or contracting.)

16 The last assumption on the third derivative is a weak sufficient condition for later results.

${ }^{17}$ We will see that the plaintiff's incentive to litigate and release information is stronger when there are more accidents waiting to happen ( $N$ is larger). If the defendants arrive in sequence then the plaintiff would, in equilibrium, either litigate in the first round or not at all.
} 
would be satisfied if, for example, the two litigants had equal litigation costs $\left(k_{p}=k_{d}\right)$ and equal bargaining power $(\theta=.5)$. This assumption implies that the plaintiff would like to avoid future accidents. If the plaintiff had too much bargaining power, for example, then he would benefit from future accidents when $\alpha$ is very large. The plaintiff would want to stimulate additional accidents for their settlement value rather than prevent them. ${ }^{18}$ This assumption also implies that settlement in the second round will be "accurate" -- reflecting the defendant's expected liability at trial.

Notice that although early litigation with $D_{l}$ involves a real costs, $k_{p}+k_{d}$, it also provides private and social benefits. In particular, the information that is verified in the courtroom -- and subsequently made public -- is used by the future defendants when making real economic decisions. It is also clear that the private and social incentives to litigate typically diverge. The decision to settle the first case involves only two of the players, $\mathrm{P}$ and $\mathrm{D}_{1}$, while the litigation decision also affects the welfare of the future defendants.

\section{Results}

The plaintiff and the first defendant face an important decision at date 1: they can settle the first case or they can take the first case to trial. The plaintiff's expected payoff at trial is $\alpha \bar{h}-k_{p}$ while the defendant's expected payments are $\alpha \bar{h}+k_{d}$. There is an obvious incentive to settle the first case: settlement avoids the total cost of litigation, $k_{p}+k_{d}$. On the other hand, litigation reveals information about future dangers and influences the precautions chosen by future defendants. We will see that the plaintiff and the first defendant may opt to

\footnotetext{
${ }^{18}$ Relaxing this assumption would create special cases associated with extreme liability rules. The main insights of the paper would not be affected, however.
} 
litigate the first case, despite the cost, if the benefit derived from informing the future defendants' effort choices is sufficiently strong.

\subsection{Equilibrium Characterization}

We will proceed by backwards induction. Suppose that first case has settled. If another accident occurs at date 2 involving defendant $D_{i}$ then the plaintiff and $D_{i}$ will remain symmetrically uninformed about the true damages, $h$. The most that $D_{i}$ is willing to pay to settle the case is $\alpha \bar{h}+k_{d}$, his expected payment if the case goes to trial. The least the plaintiff is willing to accept is $\alpha \bar{h}-k_{p}$, his expected damage award minus his litigation costs. ${ }^{19}$ Given our earlier assumption concerning the bargaining power of the two parties the case involving $D_{i}$ would settle for $S_{2}=\alpha \bar{h}$.

When viewed from date 2 , a representative defendant $D_{i}$ anticipates paying $S_{2}=\alpha \bar{h}$ in the event of an accident. He therefore chooses his precautions, $x$, to minimize his expected future liability plus his precaution costs:

$$
\operatorname{Min}_{x}(1-x) \alpha \bar{h}+c(x) .
$$

The first-order condition is,

$$
c^{\prime}(x)=\alpha \bar{h}
$$

In other words, the defendant invests to the point where his marginal cost of precautions is exactly offset by his marginal benefit associated with reducing the probability of an accident. We can write the representative defendant's precaution, $x$, as a function of the expected damages, $\bar{h}$, and the liability rule, $\alpha$ :

${ }^{19}$ For simplicity, in this paper, we assume that the threat for going to trial is always credible. 


$$
x=g(\bar{h} ; \alpha)
$$

As expected, one can show that the equilibrium precautions are increasing in the expected harm, $\bar{h}$, and the defendant's share of the damages, $\alpha$. Finally, conditional upon settling at date 1, the plaintiff's expected loss associated with the representative defendant is:

$$
L_{P}(\bar{h} ; \alpha)=[1-g(\bar{h} ; \alpha)](1-\alpha) \bar{h},
$$

the probability of an accident multiplied by the plaintiff's share of the damages.

Now suppose instead that the plaintiff and the first defendant take the first case to trial. The future defendants subsequently learn the true value of $h$ from the investigations that are made public. When making his date 2 precaution choice, our representative defendant, $D_{i}$, anticipates settling for $S_{2}=\alpha h$ in the future (should an accident arise). $D_{i}$ 's optimal precaution is now a function of the true damages $h$ rather than the average damages $\bar{h}$ :

$$
x=g(h ; \alpha) .
$$

Conditional upon pursuing a litigation strategy at date 1, the plaintiff's expected loss associated with the representative defendant is:

$$
E\left(L_{P}(h ; \alpha)\right)=\int_{0}^{\infty} L_{P}(h ; \alpha) f(h) d h
$$

where $L_{P}(h ; \alpha)$ is defined above.

We can now construct the bargaining range at date 1. The plaintiff's expected payoff conditional upon going to trial is $\alpha \bar{h}-k_{p}-(N-1) * E\left(L_{P}(h ; \alpha)\right)$, the expected damages from trial minus his expected losses associated with the future defendants. If he settles for $S_{1}$, on the other hand, his payoff would be $S_{1}-(N-1) * L_{P}(\bar{h} ; \alpha)$. Combining these expressions shows that the least that the plaintiff is willing to accept in settlement, $\underline{S_{1}}$, is:

$$
\underline{S_{1}}=\alpha \bar{h}-k_{p}+(N-1) *\left[L_{P}(\bar{h} ; \alpha)-E\left(L_{P}(h ; \alpha)\right)\right]
$$


This expression reflects the fact that litigation creates and discloses public information that subsequently affects the precautions of the defendant. The upper bound on the settlement range, or the most the first defendant is willing to pay, is simply

$$
\overline{S_{1}}=\alpha \bar{h}+k_{d}
$$

Taken together we see that settlement occurs if and only if $\underline{S_{1}} \leq \overline{S_{1}}$ or:

$$
k \geq(N-1) *\left[L_{P}(\bar{h} ; \alpha)-E\left(L_{P}(h ; \alpha)\right)\right] .
$$

Proposition 1: Define $\hat{k}=(N-1) *\left[L_{P}(\bar{h} ; \alpha)-E\left(L_{P}(h ; \alpha)\right)\right]$. If the total litigation costs are above this cutoff, $k \geq \hat{k}$, then the plaintiff and the first defendant settle out of court at date 1. If the litigation costs are below this cutoff, $k<\hat{k}$, then the first case goes to trial. Furthermore, if

(i) $\alpha=0$ then $\hat{k}=0$;

(ii) $\alpha \in(0,1)$ then $\hat{k}>0$;

(iii) $\alpha=1$ then $\hat{k}=0$.

Proof: In order to prove our result we will show that $L_{P}(h ; \alpha)$ is a strictly concave function of $h$ for $\alpha \in(0,1)$ and is linear when $\alpha=1$ and $\alpha=0$. Differentiating $L_{P}(h ; \alpha)$ with respect to $h$ twice shows us that:

$$
L_{P}{ }^{\prime \prime}(h ; \alpha)=-(1-\alpha)\left[2 g^{\prime}(h ; \alpha)+h g^{\prime \prime}(h ; \alpha)\right] .
$$

We see right away that $L_{P}{ }^{\prime \prime}(h ; 1)=0$ for all $h$ which implies that $L_{P}(\bar{h} ; 1)-E\left(L_{P}(h ; 1)=0\right.$. Recall that the representative defendant's precaution level, $x=g(h ; \alpha)$, is implicitly defined by $c^{\prime}(g(h ; \alpha))=\alpha h$. Differentiating this expression gives $g^{\prime}(h ; \alpha)=\alpha\left[c^{\prime \prime}(g(h ; \alpha))\right]^{-1}$, 
Since $c^{\prime \prime}(x)>0$ we know that this is strictly positive when $\alpha>0$ and zero when $\alpha=0$. Totally differentiating with respect to $h$ again gives $g^{\prime \prime}(h ; \alpha)=-\alpha^{2} c^{\prime \prime \prime}(x) /\left[c^{\prime \prime}(x)\right]^{-3}$, which is again strictly positive when $\alpha>0$ and $c^{\prime \prime \prime}(x)<0$ and zero otherwise. We conclude that the plaintiff's continuation payoff is linear when $\alpha=0$ and is a strictly concave function of $h$ for all $\alpha \in(0,1)$.

Q.E.D.

These results may be understood intuitively. When $\alpha=0$ the plaintiff bears all of the damages from the accident. Since the defendants bear no responsibility for the accidents they cause they take no precautions to avoid accidents $(x=0)$. At this extreme, the plaintiff gains nothing from early litigation and so the first case always settles. At the other extreme, when $\alpha=1$ the defendant bears $100 \%$ responsibility for the plaintiff's damages. The plaintiff again gains nothing from litigating the first case because his continuation losses are zero: $L_{P}(\bar{h} ; 1)=E\left(L_{P}(h ; 1)=0\right.$. In the intermediate range, $\alpha \in(0,1)$, however, the early case may go to trial in equilibrium. The future defendants respond to information by fine-tuning investments and the plaintiff captures some social value through his share, $1-\alpha$, of the damages. ${ }^{20}$

\footnotetext{
20 The result that the plaintiff derives positive value from the future actions does depend, to some extent, on the assumption that the third derivative of the cost function is non-positive. The upcoming results on the divergence between the private and social incentives to litigate do not hinge on this assumption, however.
} 


\subsection{The Divergence Between the Private and Social Incentive to Settle}

The decision of the plaintiff and the first defendant to litigate or settle at date 1 does not necessarily correspond to the efficient decision from a social welfare perspective. If the first cases settles out of court, then the future defendants choose precautions based on the average damages, $\bar{h}$. The representative defendant's expected future losses may be written as:

$$
L_{D}(\bar{h} ; \alpha)=(1-g(\bar{h} ; \alpha)) \alpha \bar{h}+c(g(\bar{h} ; \alpha))
$$

If the first case went to trial instead, the future defendants would fine-tune their precautions to the actual damage level, $h$. A representative defendant's expected loss would be:

$$
E\left(L_{D}(h ; \alpha)\right)=\int_{0}^{\infty} L_{D}(h ; \alpha) f(h) d h
$$

The next lemma states that, for all liability regimes where $\alpha>0$ (so the defendants bear some responsibility for the damages), the future defendants benefit from more information about damage levels. In short, the decision to settle the first case before investigations are conducted imposes a negative externality on future defendants.

Lemma 1: When $\alpha>0$ then $L_{D}(\bar{h} ; \alpha)>E\left(L_{D}(h ; \alpha)\right)$; future defendants strictly benefit from early litigation. When $\alpha=0$ then $L_{D}(\bar{h} ; \alpha)=E\left(L_{D}(h ; \alpha)\right)=0$; future defendants derive no value from early litigation.

Proof: To show that $L_{D}(h ; \alpha)$ is concave we take the derivative with respect to $h$. By envelope theorem we may ignore the effect of $h$ on precautions and so we have $L_{D}{ }^{\prime}(h ; \alpha)=(1-g(h ; \alpha)) \alpha$ and $L_{D}{ }^{\prime \prime}(h ; \alpha)=-\alpha g^{\prime}(h ; \alpha)$. As in the proof of Proposition 1 
we have that $g^{\prime}(h ; \alpha)=\alpha\left[c^{\prime \prime}(g(h ; \alpha))\right]^{-1}>0$ for all $\alpha>0$. Therefore $L_{D}(h ; \alpha)<0$. When $\alpha=0$, however, the future defendants take no precautions and so $L_{D}(\bar{h} ; \alpha)=E\left(L_{D}(h ; \alpha)\right)=0$.

Q.E.D.

The plaintiff and the first defendant, as shown above, will choose to settle the first case when $k \geq \hat{k}$. The future defendants, on the other hand, benefit from the information revealed through early litigation. Since the plaintiff and the first defendant do not internalize the benefit that accrues to the future defendant, there is a divergence in the direction of "too few trials".

The next proposition characterizes the optimal litigation decision from a social welfare perspective. The social planner would take into account the payoffs of all players, including the future defendants, when determining whether settlement or litigation is appropriate.

\section{Proposition 2: Define}

$$
\left.\left.\tilde{k}=(N-1) *\left[L_{P}(\bar{h} ; \alpha)\right)-E\left(L_{P}(h ; \alpha)\right)\right]+(N-1) *\left[L_{D}(\bar{h} ; \alpha)\right)-E\left(L_{D}(h ; \alpha)\right)\right] .
$$

If $k \geq \tilde{k}$ then social welfare is highest if the first case settles at date 1 and if $k<\hat{k}$ then social welfare is highest if the first case goes to trial. Furthermore, if

(i) $\quad \alpha=0$ then $\tilde{k}=\hat{k}=0$;

(ii) $\quad \alpha \in(0,1)$ then $\tilde{k}>\hat{k}>0$;

(iii) $\alpha=1$ then $\tilde{k}>\hat{k}=0$. 
Proof: Social welfare is higher with date 1 settlement when $(N-1) *\left[L_{P}(\bar{h} ; \alpha)+L_{D}(\bar{h} ; \alpha)\right] \leq(N-1) *\left[E\left(L_{P}(h ; \alpha)\right)+E\left(L_{D}(h ; \alpha)\right)\right]+k$ which gives the expression for $\tilde{k}$ in the proposition. The results follow immediately from definition of $\hat{k}$ and the previous results.

Q.E.D.

In the proposition, $\left.(N-1) *\left[L_{P}(\bar{h} ; \alpha)\right)-E\left(L_{P}(h ; \alpha)\right)\right]$ is the plaintiff and the first defendant's additional joint private benefit from litigating the first case rather than settling while $\left.(N-1) *\left[L_{D}(\bar{h} ; \alpha)\right)-E\left(L_{D}(h ; \alpha)\right)\right]$ is the joint benefit of the future defendants. When $\alpha=0$ there is no benefit from having information revealed, so it is both privately and socially optimal for all cases to settle: $\tilde{k}=\hat{k}=0$. When $\alpha>0$, then the later defendants gain surplus from early litigation, $\left.L_{D}(\bar{h} ; \alpha)\right)-E\left(L_{D}(h ; \alpha)\right)>0$, and so the socially planner would choose to go to trial more often than arises in the private equilibrium. We have the following corollary.

Corollary 1: For litigation costs in the range $k \in(\hat{k}, \tilde{k})$ the plaintiff and the first defendant choose to settle the first case even though it is in the best interest of society for the first case to go to trial. For litigation costs outside this range the private and social incentives to litigate are aligned.

\subsection{The Optimal Liability Rule}

The preceding analysis took $\alpha$, the proportion of damages borne by defendants, as 
exogenous. What if a social planner could choose the liability rule optimally instead? On the one hand, setting $\alpha=1$ will have a positive effect on the second defendant's incentives to take precautions. Taking the decision of the defendant to litigate or settle the first case as given, $\alpha=1$ better aligns the incentives of the future defendants with the incentives of society more broadly. But the social planner's choice of liability rule also affects the plaintiff's and the first defendant's decision to settle the case at date 1 . When $\alpha=1$, as shown in proposition 1, the first case would settle out of court. The information about $h$ would remain hidden, preventing the future defendants from fine-tuning their precautions.

Take instead the liability rule where $\alpha=0$, so the plaintiff and the first defendant strictly prefer to settle rather than litigate the first case. This $\alpha$ cannot be an optimal liability rule: by increasing $\alpha$ slightly while keeping the private incentive for settlement, the social planner enhances the future defendants' incentives to take precautions. Similarly, suppose that the liability rule is $\alpha<1$ such that $k<\hat{k}$, the plaintiff and the first defendant strictly prefer to litigate rather than settle the first case. This $\alpha$ cannot be an optimal liability rule: by increasing $\alpha$ slightly while keeping the incentive for litigation, we could give the future defendants stronger incentives to invest in precautions. Indeed, the optimal liability rule $\alpha^{*}$ must have the property that it is either one (so the first case settles) or it is the largest positive number that makes the plaintiff and the first defendant indifferent between litigating and settling the first case.

Proposition 3: The optimal liability parameter is either $\alpha^{*}=1$ or the largest value of $\alpha$ that 
satisfies $(N-1) *\left[L_{P}(\bar{h} ; \alpha)-E\left(L_{P}(h ; \alpha)\right] \geq k .^{21}\right.$ In the former case the first suit settles; no information is released but the future defendants are optimally deterred. In the latter case the first suit goes to trial; information is released but the future defendants take too few precautions.

This result also suggests circumstances where the private and social incentives to litigate diverge, even when the liability rule is chosen optimally. For example, if $\alpha^{*}=1$ and $k<\tilde{k}$ then the plaintiff and the first defendant may choose to settle the first case even though it is in society's interest for the first case to go to trial. The next example illustrates that this latter situation can indeed arise for a certain range of parameter values.

\subsection{Example}

Suppose that $N=2$, so there is exactly one future defendant. Suppose further that $c(x)=(1 / 2) x^{2}$ and that $f(h)$ is uniformly distributed on the unit interval $[0,1]$ so $\bar{h}=1 / 2$. Also for simplicity, suppose $\theta=1$ so that the plaintiff always requests the settlement offer, and that $k_{D}=0$ and $k_{P}=k . \quad D_{2}$ 's precaution choice takes a simple form: $x=g(h ; \alpha)=\alpha h$. P's expected future losses are $L_{P}(h ; \alpha)=(1-\alpha) h-\alpha(1-\alpha) h^{2}$ and $\mathrm{P}$ and $\mathrm{D}_{2}$ 's joint expected losses are $L(h ; \alpha)=L_{P}(h ; \alpha)+L_{D}(h ; \alpha)=h-\alpha(1-\alpha / 2) h^{2}$. Note that both are concave functions of $h$. It is easily shown that

$$
\hat{k}=\left(E\left(h^{2}\right)-\bar{h}^{2}\right) \alpha(1-\alpha)=\frac{\alpha(1-\alpha)}{12}, \text { and }
$$

\footnotetext{
${ }^{21}$ When $(N-1) *\left[L_{P}(\bar{h} ; \alpha)-E\left(L_{P}(h ; \alpha)\right]=k\right.$, the plaintiff and the first defendant are actually indifferent between settlement and litigation. We assume that the defendant will choose litigation in this knife-edged case.
} 


$$
\tilde{k}=\left(E\left(h^{2}\right)-\bar{h}^{2}\right) \alpha(1-\alpha / 2)=\frac{a(1-\alpha / 2)}{12} .
$$

Note that $\tilde{k}>\hat{k} \geq 0$ for all $\alpha \in(0,1]$ and $\tilde{k}=\hat{k}=0$ when $\alpha=0$.

Now given $k$, define the optimal liability rule be $\alpha *(k)$. From earlier result on the optimal liability rule, we must have either $\alpha^{*}(k)=1$ or the largest value $a^{*}$ that satisfies $(1 / 12) \alpha^{*}\left(1-\alpha^{*}\right) \geq k$. The largest root of this last expression is $\alpha^{*}=(1 / 2)\{1+\sqrt{1-48 k}\}$.

If $k>1 / 48$ then no root exists and therefore $\alpha *(k)=1$. The first case settles and the expected social loss is $L(\bar{h} ; 1)=3 / 8$. If $k<1 / 48$ then this root does exist. If $\alpha^{*}=(1 / 2)\{1+\sqrt{1-48 k}\}$ then the first case goes to trial and the associated expected social loss is $E\left[L\left(h ; \alpha^{*}\right)+k\right]=1 / 2-\alpha * / 3+\alpha^{2} / 6+k=1 / 2-\alpha * / 4+\alpha^{*} / 12$ (using the above equality to replace $k$ with $a^{*}$ ). If $\alpha^{*}=(1 / 2)\{1+\sqrt{1-48 k}\} \geq(3-\sqrt{3}) / 2$, (or equivalently $k \leq(2 \sqrt{3}-3) / 24)$ then the expected social loss from litigation $E\left[L\left(h ; \alpha^{*}\right)+k\right]$ is smaller than $3 / 8$ and therefore the optimal liability rule is $\alpha^{*}(k)=(1 / 2)\{1+\sqrt{1-48 k}\}<1$. If $a^{*}<(3-\sqrt{3}) / 2$, or equivalently if $k>(2 \sqrt{3}-3) / 24$, then the expected social loss from litigation is greater than $3 / 8$ and therefore the optimal liability rule is $\alpha *(k)=1$.

Finally, the private and social incentives to settle may diverge even when the liability rule is chosen optimally. When $k>(2 \sqrt{3}-3) / 24$ then $\alpha^{*}(k)=1$ and using the expressions above we find $\hat{k}=0$ and $\tilde{k}=1 / 24$. Therefore when $(2 \sqrt{3}-3) / 24<k<1 / 24$ then the plaintiff settles the first case even though it is socially efficient for the case to go to trial. When $k \leq(2 \sqrt{3}-3) / 24$ then the first case goes to trial and when $k \geq 1 / 24$ the first case settles -- private decisions that are aligned with the interests 
of society as a whole.

\section{A Simple Example with Asymmetric Information}

The previous section focused on a setting where private parties tend to settle too often. They choose to settle to avoid their private litigation costs, not internalizing the social benefits of the information made public through trial. This result may be reversed, however, when other factors are introduced. In particular, when the early litigants are privately informed they will engage in rent-seeking activities and take tough bargaining stances in an attempt to extract a greater share of the bargaining surplus. This will lead to bargaining failures and costly trials. The rent-seeking motive is purely redistributive and is not aligned with the motives of a social planner.

We modify the previous model in several ways to explore the role of asymmetric information. First, we change the information structure. Suppose that the plaintiff has private information about his harm level, $h$, when negotiating with the first defendant at date 1 and the first defendant knows that the plaintiff has this information. At date 2, the $N-1$ future defendants update their beliefs based on the disposition of the earlier case and choose their precautions accordingly. At date 3 we assume that the future defendants observe the plaintiff's damages should an accident occur so there is symmetric information at date $3 .^{22}$ We also assume that $h$ is uniformly distributed on the unit interval $[0,1]$, that the defendants' cost of precautions is quadratic, $c(x)=.5 x^{2}$, and that the defendants have the power to make take-it-or-leave-it settlement offers, so $\theta=0$. In this way, the negotiations at date 2

\footnotetext{
22 Our earlier version of this paper, HUA AND SPIER [2003], presents a more general version of this model with one defendant and two plaintiffs. In that paper, the asymmetric information is assumed to persist until date 3 .
} 
resemble the screening model in BEBCHUK [1984]. The property that $(1-\theta) k_{p}-\theta k_{d}=0$ is maintained by assuming that the plaintiff's litigation cost is zero or, alternatively, that the English Rule for allocating the litigation costs is in effect. In all other respects, however, the model here is the same as before.

Lemma 2: Suppose that the uninformed defendant, $D_{1}$, has offered to settle with the privately informed plaintiff for $S_{l}$. The continuation equilibrium features a cutoff, $h_{l}$, implicitly defined by $\alpha h_{1}+[\alpha(1-\alpha)(N-1) / 2] h_{1}^{2}=S_{1}$ if $S_{1}<\alpha+\alpha(1-\alpha)(N-1) / 2$ and $h_{1}=1$ otherwise.

(i) If $h \leq h_{1}$ then $P$ accepts $S_{1}$ at date 1 . Each of the $N-1$ future defendants take precautions $a h_{1} / 2$ each and subsequently settle out of court for $S_{2}=a h$.

(ii) If $h>h_{1}$ then $\mathrm{P}$ rejects $S_{1}$ at date 1 and goes to trial. Each of the $N-1$ future defendants take precautions $a h$ and subsequently settle out of court for $S_{2}=a h$.

Proof: We will begin at date 3 and work backwards. At date 3 the plaintiff and the defendants become symmetrically informed about damages so the defendants who caused accidents will settle out of court for $S_{2}=a h$, regardless of the outcome of the earlier case. The outcome of the earlier case will affect the defendants' precautions at date 2 , however. If the first case went to trial then the representative defendant learns the true damages and sets $c^{\prime}(x)=a h$, giving $x=a h$. If the first case settled then the representative defendant knows that the plaintiff's damages are in the truncated uniform distribution on $\left[0, h_{1}\right]$, so the expected harm is $h_{l} / 2$. The defendant therefore takes precautions $x=a h_{l} / 2$. 
Now let's consider the plaintiff's decision about whether to accept an offer at date 1 . In general, a plaintiff of type $h$ has an expected future loss $(N-1)(1-x)(1-\alpha) h$, the number of future defendants multiplied by the probability of an accident multiplied by the plaintiff's share of the damages. These losses influence the plaintiff's decision to accept a settlement offer, $S_{1}$. If the plaintiff accepts $S_{1}$ he gets $S_{1}-(N-1)\left(1-a h_{1} / 2\right)(1-\alpha) h$ and if he rejects $S_{1}$ and goes to trial he gets $\alpha h-(N-1)(1-a h)(1-\alpha) h$. Setting these two expressions equal to each other we find the interior value for $h_{l}$ as defined in the lemma (if an interior solution exists); otherwise, $h_{l}=1$ and all types settle out of court.

Q.E.D.

Lemma 3: $D_{1}$ 's optimal cutoff, $\hat{h}$, is the positive root of the following quadratic expression $\alpha \hat{h}+(3 / 2)(N-1) \alpha(1-\alpha) \hat{h}^{2}-k=0$ when that root is smaller than 1 and $\hat{h}=1$ otherwise. The social planner's optimal cutoff, $\tilde{h}$, is the positive root of $(1 / 4)(N-1) \alpha(1-\alpha / 2) \tilde{h}^{2}-k=0$ when that root is smaller than 1 and $\tilde{h}=1 \quad$ otherwise.

Proof: The first defendant chooses $h_{l}$ to minimize his expected payments to the plaintiff.

$$
\underset{h_{l}}{\operatorname{Min}} \quad \int_{0}^{h_{l}}\left\{a h_{1}+[\alpha(1-\alpha)(N-1) / 2] h_{l}^{2}\right\} d h+\int_{h_{l}}^{l}[\alpha h+k] d h .
$$

The first term captures the settlement payments to the plaintiff types below the cutoff and the second term are the defendant's payments at trial associated with the plaintiff types above the cutoff. Differentiating this expression once gives the first-order condition defining $\hat{h}$ in the Lemma and it is easy to see that the second-order condition holds. The social planner, on the other hand, would choose the cutoff $h_{l}$ to minimize the social losses, which include the 
litigation costs at date 1 , the precautions at date 2 , and the accident losses at date 3 :

$$
\begin{aligned}
\operatorname{Min}_{h_{l}} & {\left[1-h_{l}\right] k } \\
& +(N-1)\left\{\int_{0}^{h_{l}}\left[\left(1-a h_{l} / 2\right) h+(1 / 2)\left(\alpha h_{l} / 2\right)^{2}\right] d h+\int_{h_{l}}^{l}\left[(1-a h) h+(1 / 2)(\alpha h)^{2}\right] d h\right\}
\end{aligned}
$$

Differentiating this expression gives the social planner's optimal cutoff, $\tilde{h}$, as in the lemma. The second-order condition holds.

Q.E.D.

The next two propositions characterize the nature of the divergence between the private and social incentives to litigate and the optimal liability rule for the interesting case where the cutoffs, $\tilde{h}$ and $\hat{h}$, are both interior. In other words, we restrict attention to cases where there is at least some litigation in equilibrium.

Proposition 4: If $a<10 / 11$ then there are too many trials in equilibrium $(\hat{h}<\tilde{h})$. If $a>10 / 11$ then there exists a finite and positive cutoff, $\gamma^{*}(\alpha)=8 \alpha(2-\alpha) /(11 \alpha-10)^{2}$. If $(N-1) k>\gamma^{*}(\alpha)$ then there are too few trials in equilibrium $(\hat{h}>\tilde{h})$ and if $(N-1) k<\gamma^{*}(\alpha)$ then there are too many trials in equilibrium $(\hat{h}<\tilde{h})$.

Proof: Consider the first order conditions in the previous lemma, and define $\hat{g}(h)=\alpha h+(3 / 2)(N-1) \alpha(1-\alpha) h^{2}-k \quad$ and $\quad \tilde{g}(h)=(1 / 4)(N-1) \alpha(1-\alpha / 2) h^{2}-k$. These are increasing functions of $h$ and take on the value $O$ at the values $\hat{h}$ and $\tilde{h}$, respectively. They cross at two points, zero and $h^{\prime}=\left(\frac{8}{N-1}\right)\left(\frac{1}{11 a-10}\right) . \quad$ If $\quad a<10 / 11$ 
then $h^{\prime}<O$ and, since $\hat{g}(O)=\tilde{g}(O)=-k$ and $\hat{g}^{\prime}(O)>\tilde{g}^{\prime}(O)$ we know that $\hat{g}(h)>\tilde{g}(h)$ for all $\mathrm{h}>0$. We therefore conclude that $\hat{h}<\tilde{h}$. If $a>10 / 11$ then $h^{\prime}>0$ and so $\hat{g}(h)>\widetilde{g}(h)$ for all $0<h<h^{\prime}$ and $\hat{g}(h)<\tilde{g}(h)$ for all $h>h^{\prime}$. Using the definition of $\tilde{h}$ in the lemma we see that when $(N-1) k>\gamma^{*}(\alpha)$ then $\tilde{h}>h^{\prime}$ and so $\hat{h}>\tilde{h}$. If $(N-1) k>\gamma^{*}(\alpha)$, on the other hand, then $\tilde{h}<h^{\prime}$ and so $\hat{h}<\tilde{h}$.

Q.E.D.

The result that there may be either too many or too few trial in equilibrium shouldn't be too surprising. On one hand, the first defendant tries to seek rent from the privately informed plaintiff; on the other hand, the early litigants incorporates only a part of the future value of more accurate information from trial. The former gives the incentive for early litigants to have too many trials; while the latter offers the incentive to have too few trials. Proposition 4 tells us that the trade-off depends on the liability rule, the number of litigants, and the litigation costs. Note that the private and social incentives are aligned only in the knife-edged case where $(N-1) k=\gamma *(\alpha)$.

Proposition 5: Let $\hat{h}(\alpha)$ be $\mathrm{D}_{1}$ 's optimal cutoff. The optimal liability rule is either $\alpha^{*}=1$ or one of the values satisfying:

$\left[(1 / 4)(N-1) \alpha^{*}\left(1-\alpha^{*} / 2\right) \hat{h}\left(\alpha^{*}\right)^{2}-k\right]\left(\partial \hat{h} / \partial \alpha^{*}\right)+(1 / 3)(N-1)\left[\left(\alpha^{*}-1\right)\left(1-\hat{h}\left(\alpha^{*}\right) / 4\right)\right]=0$.

where $\partial \hat{h} / \partial \alpha^{*}=-\left[\hat{h}+(3 / 2)(N-1)\left(1-2 \alpha^{*}\right) \hat{h}^{2}\right] /\left[\alpha^{*}+3(N-1) \alpha^{*}\left(1-\alpha^{*}\right) \hat{h}\right]$ for $0<\hat{h}<1$.

Proof: The social planner chooses the liability parameter $\alpha$ to minimize the social loss: 


$$
\begin{aligned}
& \operatorname{Min}_{\alpha}[1-\hat{h}(\alpha)] k+(N-1)\left\{\int_{0}^{\hat{h}(\alpha)}\left[(1-a \hat{h}(\alpha) / 2) h+(1 / 2)(\alpha \hat{h}(\alpha) / 2)^{2}\right] d h\right. \\
& \left.+\int_{\hat{h}(\alpha)}^{1}\left[(1-a h) h+(1 / 2)(\alpha h)^{2}\right] d h\right\}
\end{aligned}
$$

Differentiating this expression gives the marginal effect as given in the left hand side of (11) where $\partial \hat{h} / \partial \alpha^{*}$ for $0<\hat{h}<1$ is found from the expression in Lemma 3. If $\alpha^{*}=0$ then $\hat{h}=0$ and $\partial \hat{h} / \partial \alpha^{*}=0$. Therefore, the marginal loss in (11) is negative so that $\alpha^{*}=0$ cannot be optimal. $\alpha^{*}$ is either 1 or one of the values satisfying (11).

Q.E.D.

When choosing a liability rule, the social planner must consider both the early litigants' incentives to pursue litigation and the future defendants' incentives to take precautions. This trade-off gives the optimal rule characterized in (11). The first term of (11) is the indirect marginal effect on social welfare when changing the liability rule changes the equilibrium number of trials. The second term is direct marginal effect on welfare when changing the liability rule changes the future defendants' precautions. With the optimal liability rule, if there were no divergence $(\hat{h}=\tilde{h}<1)$ then it would be always better to increase the liability parameter to induce more precautions. Therefore, the private and social desirability for litigation are not aligned even when the liability rule is chosen optimally.

\section{Conclusion}

This paper has explored a new efficiency rationale for litigation. The public information created by legal investigations creates economic value when future actors 
fine-tune their decisions in response to the information revealed through litigation activities. In contrast, when early cases settle before thorough investigations are conducted then a negative externality is imposed on the future actors. This rationale suggests an important tradeoff in the design of liability rules. First, imposing liability on long-run players (the plaintiff in our model) provides those players with greater incentives to litigate early claims. When held liable for future harms, the long-run players benefits from the improvement in public information that results from their litigation activities. On the other hand, shifting liability to the long-run players dampens the incentives of future players (defendants in our model) to mitigate their risks.

Our basic framework may be extended in a number of ways. First, one could generalize the liability rule to consider decoupled damages (see POLINSKY AND CHE [1991]). Assuming that the plaintiff pursues all claims, making the defendants in our model responsible for $100 \%$ of the harm that they cause leads the defendants to invest appropriately in accident avoidance activities. Awarding the plaintiff less than $100 \%$ would create greater incentives for the plaintiff to litigate. This scheme could, for example, be implemented by taxing the plaintiffs' award. The framework could also be extended to condition the liability rule on the order of arrival. In a richer framework, placing less responsibility on the defendant (and more on the plaintiff) should be more valuable in early cases where the potential for learning is higher. Our model has also abstracted from accident avoidance activities of the plaintiff -the plaintiff as well as the defendant may be able to take precautions to reduce the risk of future accidents. $^{23}$

23 The earlier version of this paper, HUA AND SPIER [2003], considered the analogous problem of one defendant facing a sequence of plaintiffs who take precautions. The defendant's incentives were ignored, however. 
Finally, note that since the future defendants value the information created through litigation they have a joint incentive to subsidize the first defendant's litigation costs. We have, of course, ignored this possibility. Free-riding among the possible defendants and the difficulty of drafting contracts that earmark contributions to accurate investigations may, in practice, preclude subsidies along these lines. Alternatively, they may be able to overcome the collective action problem through insurance contracts with a common insurer ${ }^{24}$ Never-the-less, these positive externalities suggest that the joining of defendants, present and future, into a defendant class action could be a more efficient arrangement. These, and other issues, remain topics for future research.

\section{References}

BEBCHUK, L. [1984], "Litigation and Settlement Under Imperfect Information," RAND Journal of Economics, 15, 404-415.

Carlton, J., "Group Seeks to Add \$100 Million to Bill for Exxon Oil Spill," Wall Street Journal, August 30, 2001.

CHE, Y.-K. [1996], "Equilibrium Formation of Class Action Suits," Journal of Public Economics, 62, 339-61.

[2002], "The Economics of Collective Negotiations in Pretrial Bargaining," The International Economic Review, 43, 549-76.

CHE, Y.-K. AND YI, J.G. [1993], "The Role of Precedents in Repeated Litigation," Journal of Law, Economics, and Organization, 9, 399-424.

Daughety, A.F. [2000], "Settlement, " in: B. Bouckaert and G. De Geest, eds., Encyclopedia of Law and Economics, Vol. 5, Edward Elgar Publishing Co.

Daughety, A. F. AND ReInganum, J.F. [1999], "Hush Money," RAND Journal of Economics, 30, 661-78.

${ }^{24}$ We thank Eric Talley for pointing out this possibility. 
AND —. [2002], "Information Externalities in Settlement Bargaining: Confidentiality and Correlated Culpability," RAND Journal of Economics, 33, 587-604.

Dewatripont, M. AND J. TiRole [1999], "Advocates," Journal of Political Economy, 107, 1-39.

HAY, B. AND SPIER, K.E. [1998], “Settlement of Litigation,” pp. 442-451 in: P. Newman (ed.), The New Palgrave Dictionary of Economics and the Law, Macmillan Reference Limited: London.

HuA, X, AND SPIER, K.E., [2003] "On the Value of Information in Sequential Litigation," Kellogg School of Management Mimeo.

KaPlOw, L. [1998],"Accuracy in Adjudication," pp. 1-7 in: P. Newman (ed.), The New Palgrave Dictionary of Economics and the Law, Macmillan Reference Limited: London.

KAPlOW, L., AND SHAVELl, S. [1996], "Accuracy in the Assessment of Damages," Journal of Law and Economics, 39, 191-210.

AND — [1994], "Accuracy in the Determination of Liability," Journal of Law and Economics, 37, 1-15.

Kornhauser, L. And Revesz, R. [1994A], "Multidefendant Settlements: The Impact of Joint and Several Liability," Journal of Legal Studies, 23, 41-76.

AND_— [1994b],"Multidefendant Settlements Under Joint and Several Liability: The Problem of Insolvency," Journal of Legal Studies, 23, 517-42.

Miller, G. [1998], “Class Actions,” pp. 257-262 in: P. Newman (ed.), The New Palgrave Dictionary of Economics and the Law, Macmillan Reference Limited: London.

Polinsky, A. M. And CHE, Y.-K. [1991], "Decoupling Liability: Optimal Incentives for Care and Litigation," Rand Journal of Economics, 22, 562-570.

SHAVELL, S. [1997],"The Fundamental Divergence between the Private and the Social Motive to Use the Legal System," The Journal of Legal Studies, 26, 575-612.

SPIER, K.E. [1994a], "Settlement Bargaining and the Design of Damage Awards," Journal of Law, Economics, \& Organization, 10, 84-95.

[1994b], "Pretrial Bargaining and the Design of Fee-shifting Rules. RAND Journal of Economics, 25, 197-214. 
[1997], “A Note on the Private Versus Social Incentive to Settle Under a Negligence Rule," The Journal of Legal Studies, 26, 613-21.

_ [2002], "Settlement with Multiple Plaintiffs: The Role of Insolvency," Journal of Law, Economics, and Organization, 18, pp. 295-323.

_ [2003], "The Use of Most-Favored-Nation Clauses in Settlement of Litigation," The RAND Journal of Economics, 34, 78-95. 295-323.

SPIER, K.E. AND SYKeS, A. O. [1998], "Capital Structure, Priority Rules, and the Settlement of Civil Claims," The International Review of Law and Economics, 18, 187-200.

WiLkinson, T. [2002], "After 13 Years, Valdez's Oil Damage Lingers," Christian Science Monitor, October 29. 